\title{
Development and characterization of a symbiotic cheese added with Saccharomyces boulardii and inulin
}

\author{
Rafael Zamora-Vega ${ }^{1}$, José Luis Montañez-Soto ${ }^{1 *}$, José Venegas-González ${ }^{1}$, Aurea \\ Bernardino-Nicanor ${ }^{2}$, Leopoldo González $\mathrm{Cruz}^{2}$ and Héctor Eduardo Martínez-Flores ${ }^{3}$ \\ ${ }^{1}$ Instituto Politécnico Nacional, Centro Interdisciplinario de Investigación para el Desarrollo Integral Regional, Unidad \\ Michoacán. Justo Sierra 28. C.P. 59510. Jiquilpan, Mich. México. \\ ${ }^{2}$ Instituto Tecnológico de Celaya. Avenida Tecnológico y García Cubas s/n. C.P. 38010. Celaya, Gto. México. \\ ${ }^{3}$ Facultad de Químico-Farmacobiología, Universidad Michoacana de San Nicolás de Hidalgo, Tzintzuntzan 173, Col. \\ Matamoros. Morelia, Mich, México.
}

Accepted 22 May, 2013

\begin{abstract}
The aim of this work was to develop and characterize a functional food (fresh cheese) by incorporation of a probiotic microorganism (Sacharomyces boulardii) and a prebiotic agent (inulin), both encapsulated with sodium alginate and cactus mucilage. The microorganism viability incorporated in the fresh cheese in free and encapsulated form was evaluated at the beginning and the end of the cheese shelf life. The organoleptic characteristics (color, odor, taste, texture and overall acceptability) of the elaborated cheese were evaluated too. The viability of the probiotic microorganism added in encapsulated form was greater than that shown by the microorganism added unencapsulated, after 30 days of keeping the cheeses at $4^{\circ} \mathrm{C}$. The addition of the symbiotic $S$. boulardii e inulin did not alter the chemical composition of the cheese, but improves its organoleptic properties and makes it more acceptable to consumers. The viability of microorganisms during all cheese shelf life satisfies the minimum quantity recommended by the Food and Agriculture Organization for this cheese is considered as probiotic food.
\end{abstract}

Key words: Saccharomyces boulardii, symbiotic cheese, probiotic, prebiotic, inulin.

\section{INTRODUCTION}

In the fourth century $\mathrm{BC}$, the medicine father Hippocrates (460-370 BC), coined the popular phrase "Let food be your medicine and medicine be your food", which emphasizes the role of foods in disease prevention and recognizes an additional function for foods, plus to provide nutrient for the good performance of our body. Recently in 1989 Dr. Stephen Defelice coined the word "nutraceutical" (blend of nutrition and pharmaceutical) and he defined it as any food or parts of a food that provides medical or health benefits, including the prevention and treatment of diseases". The term "functional food" has also been used as indistinct way to refer to this type of foods or food products (Yadav et al., 2012).

The development of functional foods began in earnest in Japan in the early eighties with advances in chemical

*Corresponding author. E-mail: jmontanez@ipn.mx. Tel: 353-53-302-18.

Abbreviations: FOSHU, Foods for Specified Health Use; BMA, bacteria mesophilic aerobic; FAO, Food and Agriculture Organisation; PDA, potato dextrose agar; TCO, total coliforms organisms; CFU, Colony Forming Units. 
identification of bioactive compounds, processing and formulation of foods as well as elucidation of molecular mechanisms involved in the modulation of metabolic disorders. The initial regulatory environment for functional foods was established by Japan in 1991 with the introduction of "foods for specified health use" (FOSHU), which were developed to improve health and reduce the risk of disease. The demand for this type of food has grown in Asian countries from the late twentieth and recently its use has spread rapidly to countries in Europe, Africa and America (Buts et al., 2006). Nowadays, research and development of new functional foods is based on the study of microorganisms probiotics and some groups of chemicals found in plant foods such as prebiotics, flavonoids, terpenes, carotenoids, phytoestrogens, beta-glucan, fatty acids $\Omega-3$ and $\Omega-6$, between major, in order to prove their biological activity and potential beneficial effect on health (Ramirez, 2009).

The probiotics are live microorganisms which exert a beneficial effect on the health of the host when they are administered in adequate quantities (FAO/WHO, 2002), while prebiotics are non-digestible food ingredients, whose purpose is to serve as food for the probiotic microorganism and thus increase their survival chances and implantation in the host intestinal tract. Inulin and fructooligosaccharides are the more important prebiotics ingredients contained in foods (Ziemer and Gibson, 1998). Current research tends to use prebiotics and probiotics in the development of functional foods called "symbiotic food", that is, those foods that contain both probiotic cells as prebiotic ingredients (Araujo et al., 2009).

Both in laboratory as in food industry, the yogurt, cheese, ice cream and others fermented dairy products has been the main foods used as vehicle of probiotic microorganism, that is, prebiotic ingredients, either for the development of probiotics food, prebiotics food, or symbiotic food (Stanton et al., 2001; Granato et al., 2010; Eliana et al., 2013). In many countries the yogurt is considered a child food and it is not consumed by the general population, by that, it is necessary to develop other functional foods that reach all segments of the population (Sanders, 2008).

An alternative functional milk product with a consumption period potentially longer is cheese whose food matrix has a protective effect for probiotic microorganisms, increasing thus their chances of surviving the harsh conditions of the gastrointestinal tract, until they reach the colon, where these microorganisms are implanted and exert their beneficial effects on host health (Andrade et al., 2012).

Within microorganisms classified as probiotics, exist some yeasts such as Saccharomyces boulardii, which is a natural yeast isolated from the bark of "litchi" in Indochina. It is a safe microorganism, non-toxic, nonpathogenic; also it is a thermophilic microorganism resistant to gastric acidity and proteolysis, so it can be implanted in large quantities in the gastrointestinal tract, maintaining constant levels of viability (Macfarland and Bernasconi, 1996). There has been some research on the use of this yeast as a potential agent for the biotherapeutic treatment of microorganisms associated with diarrhea and colitis (Buts et al., 2006). Also, viable cells of this yeast have been recently used to improve the resistance of the intestinal ecosystem for bacterial infections (Abosereh, 2007); however, there are not reports in which this yeast is used as a probiotic ingredient in the development of a functional food, thus becoming an attractive investigation subject.

The objective of this study was: (1) to develop symbiotic cheese with the addition of $S$. boulardii and inulin; (2) to determine the composition, the sanitary quality and the organoleptic properties of the obtained symbiotic cheese and; (3) to follow the viability of the probiotic microorganism $S$. boulardii, during the shelf life of the symbiotic cheese, stored at $4^{\circ} \mathrm{C}$

\section{MATERIALS AND METHODS}

\section{Raw material}

Sodium alginate Protanal SF 120 (Biopolymers, USA), inulin (Megafarma, Mexico), cladodes from Opuntia ficus-indica to obtain the cactus mucilage and raw milk to elaborate the cheese, both products were acquired in the local market of Jiquilpan, Mich. Mexico.

\section{Probiotic yeast}

The S. boulardii (strain CDBB-L-1483 ATCC-MYC-797) was acquired in CINVESTAV-IPN (México). The probiotic yeast was kept in refrigeration at $4^{\circ} \mathrm{C}$ in PDA (BIXON, Mexico) and activated when it was required. To achieve this, the strain was proliferated in nutrient broth (BIXON, Mexico) at $30^{\circ} \mathrm{C}$, until a concentration of $10^{10}$ $\mathrm{CFU} / \mathrm{g}$ was obtained.

\section{Development of functional food}

The symbiotic cheese was made according to the method proposed by Sangronis and Garcia (2007), which is as follows: Initially cow's milk $(30 \mathrm{~L})$ was pasteurized at $75^{\circ} \mathrm{C}$ for $30 \mathrm{~min}$ and cooled to $34^{\circ} \mathrm{C}$, at which time was added $30 \mathrm{~mL}$ of rennet (Cuamex, Mexico) plus 3 $\mathrm{g}$ of $\mathrm{CaCl}_{2}$ (Cuamex, Mexico) and the mixture was homogenized by stirring. The mixture was kept on standing for a period of $60 \mathrm{~min}$, time in which performs the coagulation of milk. After, the curd was cut to facilitate the draining, after completion, this was added to 120 $\mathrm{g}$ of food grade $\mathrm{NaCl}$ and then the curd was mixed by hand for 5 min to homogenize the mixture. Thereafter the curd was divided into three portions of $1 \mathrm{~kg}$ each. The first portion (Q1), both, the probiotic microorganism and inulin as prebiotic ingredient were added in a free state, that is, unencapsulated. The second portion $\left(Q_{2}\right)$ the simbiont was added previously encapsulated with sodium alginate, inulin and cactus mucilage (Zamora et al., 2012), both in an amount such that curd have a final concentration of $10^{9} \mathrm{CFU} / \mathrm{g}$. The third portion $\left(Q_{3}\right)$ served as control and the simbiont was not added. Again all ingredients were mixed manually for 5 min in order to homogenize the mixture and then the cheeses were made in special molds of $10 \mathrm{~cm}$ diameter by $2 \mathrm{~cm}$ in depth. Finally, the cheeses were packed in wax paper placed in a plastic bag and kept refrigerated at $4^{\circ} \mathrm{C}$ for their subsequent evaluations. 


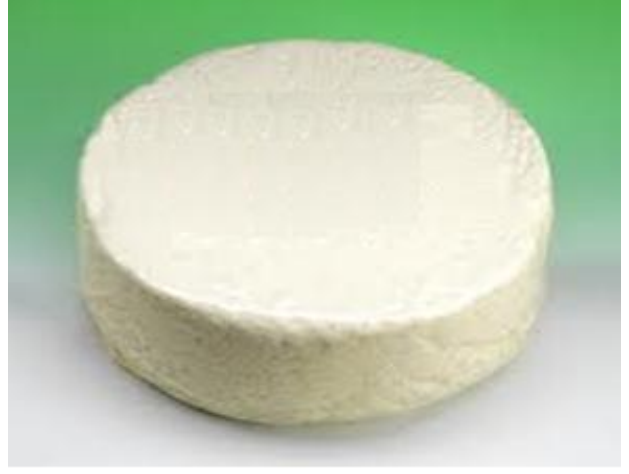

Figure 1. Fresh cheese.

\section{Bromatological analysis of the functional food}

The bromatological analysis of the functional cheeses were performed according to the methodology proposed by the AOAC (2004), thus the content of moisture, ash, fats, proteins and finally, total carbohydrates content was determined by difference to $100 \%$. The $\mathrm{pH}$ determination was made according to the Mexican Official Norms (MON-F-099-1970). All of these analyzes were performed in triplicate and in two stages. The first when the cheeses were freshly made and the second after cheeses were stored refrigerated at $4^{\circ} \mathrm{C}$.

\section{Viability of the probiotic microorganism in the functional food}

The viability of the yeast cells added to cheese, either free or encapsulated state was determined by the pour plate method in PDA medium (Bixon, Mexico), incubated at $30^{\circ} \mathrm{C}$ for $72 \mathrm{~h}$. Initially 1 $\mathrm{g}$ samples of cheese were dispersed in $10 \mathrm{~mL}$ of diluent (peptone water). The release of encapsulated microorganisms was performed according to the method of Yañez et al. (2002). Four repetitions were performed for each treatment. Thus the probiotic microorganism viability was determined versus storage time, performing counts of viable microorganisms once a week during four weeks. The first determination were performing at zero time, that is, the analysis were done the same day that the cheeses were made.

\section{Sanitary quality of the functional food}

The sanitary quality of cheeses was evaluated according to the methodology proposed in Mexican Official Norms. The content of bacteria mesophilic aerobic (BMA) was determined for (MON-092SSA1-1994), fungi and yeasts (MON-111-SSA-1-1994), Total Coliform Organisms (TCO) (MON-113-SSA1-1994), Salmonella (MON-114-SSA1-1994), S. aureus (MON-115-SSA1-1994), and determination of Escherichia coli was performed by the MUG + fluorescence method.

\section{Sensory evaluation}

Sensory analysis consisted in evaluating the sensory characteristics that present the symbiotic cheese and compare them with a commercial cheese used as control. A five-point hedonic scale was used and the attributes evaluated were: Color, odor, flavor, texture and overall acceptability. Sixty (60) students of the San Nicolas de
Hidalgo Michoacan University were employed as judges. A tasting panel was installed with the two samples, the first with the symbiotic cheese and the second with the commercial fresh cheese. After giving judges to test each sample, water were given to rinse their mouth vigorously and were given a sheet of paper with the parameters to be evaluated for each sample.

\section{Statistical analysis}

The experiment was designed as a randomized complete block with four replicates. The cheeses with the free and capsulated microorganisms were analyzed. All determinations were performed in triplicate and data were presented as the mean value. Cell counts obtained by the pour plate method were converted into logarithm values and an analysis of variance (ANOVA) was used to test for differences over time for each condition, where $\mathrm{P}<0.05$ was considered statistically different. All statistical analysis were performed with the Statistical Analysis Software version 9.0 program (SAS Inst. Inc., Cary, N.C., U.S.A.).

\section{RESULTS}

The selected food type to be used as vehicle of the probiotic microorganism was fresh cheese (Figure 1), because this type of cheese is the main cheese consumed in our country and it is consumed by people of all age. The bromatological analysis results of the different elaborated cheeses are presented in Table 1. The symbiont added did not impact significantly both the initial as the final chemical composition of the cheeses. During storage under refrigeration at $4^{\circ} \mathrm{C}$, the cheeses tend to dehydrate which results in the loss of $18.54+$ $0.30 \%$ of its initial weight and therefore, the concentration in the same proportion of all its components. After 4 weeks of storage under refrigeration at $4^{\circ} \mathrm{C}$, the cheeses $\mathrm{pH}$ increased slightly from 4.9 to 5.4 units (Table 2). The final $\mathrm{pH}$ of all cheeses was slightly higher than its initial $\mathrm{pH}$, probably due to the effect of syneresis presented during the cheeses storage in which, the water-soluble molecules such as lactose and organic acids of low molecular weight, such as lactic acid initially present in the cheese, leaving the casein matrix was drained, resulting in a slight increase in $\mathrm{pH}$ of all cheeses.

\section{Sanitary quality of the functional food}

The concentration of all pathogen microorganisms in the different cheeses (Table 3 ), was below the maximum allowable limits by the corresponding Official Mexican Standard for each one of the microorganisms evaluated, which means that the milk was pasteurized properly and then all steps of cheese making, adequate measures security and hygiene were applied.

\section{Viability of the microorganism in functional food}

The viability of the probiotic microorganism decreased 
Table 1. Bromatologic analysis of the different cheeses.

\begin{tabular}{llccc}
\hline Parameter & Phase & $\mathbf{Q}_{1}$ & $\mathbf{Q}_{\mathbf{2}}$ & $\mathbf{Q}_{3}$ \\
\hline \multirow{2}{*}{ Moisture } & Initial & $54.83 \pm 0.95^{\mathrm{a}}$ & $55.33 \pm 1.15^{\mathrm{a}}$ & $54.66 \pm 1.15^{\mathrm{a}}$ \\
& Final & $44.59 \pm 1.12^{\mathrm{a}}$ & $45.23 \pm 1.32^{\mathrm{a}}$ & $44.53 \pm 0.19^{\mathrm{a}}$ \\
\multirow{2}{*}{ Ashes } & Initial & $4.28 \pm 0.20^{\mathrm{a}}$ & $4.31 \pm 0.37^{\mathrm{a}}$ & $4.54 \pm 0.24^{\mathrm{a}}$ \\
& Final & $5.09 \pm 0.14^{\mathrm{a}}$ & $5.10 \pm 0.14^{\mathrm{a}}$ & $5.28 \pm 0.14^{\mathrm{a}}$ \\
\multirow{2}{*}{ Fat } & Initial & $19.86 \pm 0.47^{\mathrm{a}}$ & $19.66 \pm 0.35^{\mathrm{a}}$ & $19.56 \pm 0.70^{\mathrm{a}}$ \\
& Final & $23.60 \pm 1.56^{\mathrm{a}}$ & $23.25 \pm 1.40^{\mathrm{a}}$ & $23.18 \pm 1.34^{\mathrm{a}}$ \\
\multirow{2}{*}{ Proteins } & Initial & $17.94 \pm 0.37^{\mathrm{a}}$ & $17.76 \pm 0.53^{\mathrm{a}}$ & $18.45 \pm 0.21^{\mathrm{a}}$ \\
& Final & $21.32 \pm 0.21^{\mathrm{a}}$ & $21.00 \pm 0.22^{\mathrm{a}}$ & $21.87 \pm 0.96^{\mathrm{a}}$ \\
\multirow{2}{*}{ Carbohydrates } & Initial & $3.09 \pm 0.15^{\mathrm{a}}$ & $2.94 \pm 0.18^{\mathrm{a}}$ & $2.79 \pm 0.16^{\mathrm{a}}$ \\
& Final & $5.40 \pm 0.25^{\mathrm{a}}$ & $5.42 \pm 0.26^{\mathrm{a}}$ & $5.14 \pm 0.24^{\mathrm{a}}$ \\
\hline
\end{tabular}

Data in the same row with a different letter are significantly different $(p<0.05)$.

Table 2. Variation of the $\mathrm{pH}$ of the different cheeses.

\begin{tabular}{lcc}
\hline \multirow{2}{*}{ Cheese } & \multicolumn{2}{c}{$\mathrm{pH}$} \\
\cline { 2 - 3 } & Initial & Final \\
\hline $\mathrm{Q}_{1}$ & $4.9 \pm 0.03^{\mathrm{a}}$ & $5.1 \pm 0.05^{\mathrm{a}}$ \\
$\mathrm{Q}_{2}$ & $5.1 \pm 0.04^{\mathrm{b}}$ & $5.3 \pm 0.05^{\mathrm{b}}$ \\
$\mathrm{Q}_{3}$ & $5.2 \pm 0.05^{\mathrm{b}}$ & $5.4 \pm 0.04^{\mathrm{b}}$ \\
\hline
\end{tabular}

Data in the same column with different letter are significantly different $(p<0.05)$.

Table 3. Microbiological analysis of the different cheeses.

\begin{tabular}{lccc}
\hline \multirow{2}{*}{ Microorganism } & \multicolumn{3}{c}{ Cheese } \\
\cline { 2 - 4 } & $\mathbf{Q}_{\mathbf{1}}$ & $\mathbf{Q}_{\mathbf{2}}$ & $\mathbf{Q}_{\mathbf{3}}$ \\
\hline BMA & $3.15 \times 10^{4}$ & $2.91 \times 10^{4}$ & $7.15 \times 10^{4}$ \\
L. monocytogenes & Negative & Negative & Negative \\
TCO & $<100$ & $<100$ & $<100$ \\
Salmonella & Negative & Negative & Negative \\
S. aureus & 420 & 513 & 879 \\
Escherichia coli & Negative & Negative & Negative \\
\hline
\end{tabular}

with the storage time in refrigeration at $4^{\circ} \mathrm{C}$ in both cheeses, as in the elaborated with the symbiont encapsulated (Table 4). The viable cell count decreased in all cheeses during its storage time in refrigeration at $4^{\circ} \mathrm{C}$. Comparatively, the lower loss of viability of $S$. boulardii occurred in the cheese added with the symbiont encapsulated, whereby, we can say that the microcapsule made with inulin, sodium alginate and cactus mucilage had a protective effect on the microorganism.

\section{Sensory evaluation}

Figure 2 shows the results obtained of the sensory evalua- tion of the cheeses elaborated, one of them with the encapsulated symbiont ( $S$. boulardii e inulin), and the other cheese that was made without symbiont and this acted as the control cheese. There were no statistically significant differences $(p>0.05)$ in the degree of acceptance of the judges with respect to the color, flavor and smell of the cheeses supplemented with probiotic microorganisms inulin with respect to control cheese (without addition of the symbiont $S$. boulardii e inulin), properties that are desirable because they do not affect the consumer perception. The sensory attribute did observe a statistically significant difference $(p<0.05)$; it was between texture of the probiotic cheeses and texture of the control cheese and hence, in their acceptability by consumers. 
Table 4. Decrease of viability of Saccharomyces boulardii in the different cheeses with the storage time.

\begin{tabular}{lccccc}
\hline \multirow{2}{*}{ Cheese } & \multicolumn{5}{c}{ Storage time (weeks) } \\
\cline { 2 - 6 } & $\mathbf{0}$ & $\mathbf{1}$ & $\mathbf{2}$ & $\mathbf{3}$ & $\mathbf{4}$ \\
\hline $\mathrm{Q}_{1}$ & $9.04 \pm 0.06^{\mathrm{a}}$ & $8.05 \pm 0.09^{\mathrm{b}}$ & $7.30 \pm 0.13^{\mathrm{b}}$ & $6.87 \pm 0.08^{\mathrm{b}}$ & $6.15 \pm 0.50^{\mathrm{b}}$ \\
$\mathrm{Q}_{2}$ & $9.17 \pm 0.08^{\mathrm{a}}$ & $8.66 \pm 0.31^{\mathrm{a}}$ & $8.26 \pm 0.49^{\mathrm{a}}$ & $8.08 \pm 0.44^{\mathrm{a}}$ & $7.50 \pm 0.02^{\mathrm{a}}$ \\
$\mathrm{Q}_{3}$ & $5.72 \pm 0.05^{\mathrm{b}}$ & $5.14 \pm 0.04^{\mathrm{c}}$ & $4.84 \pm 0.21^{\mathrm{c}}$ & $3.13 \pm 0.09^{\mathrm{c}}$ & $3.04 \pm 0.03^{\mathrm{c}}$ \\
\hline
\end{tabular}

Means in the same column with different superscripts are significantly different $(p<0.05)$.
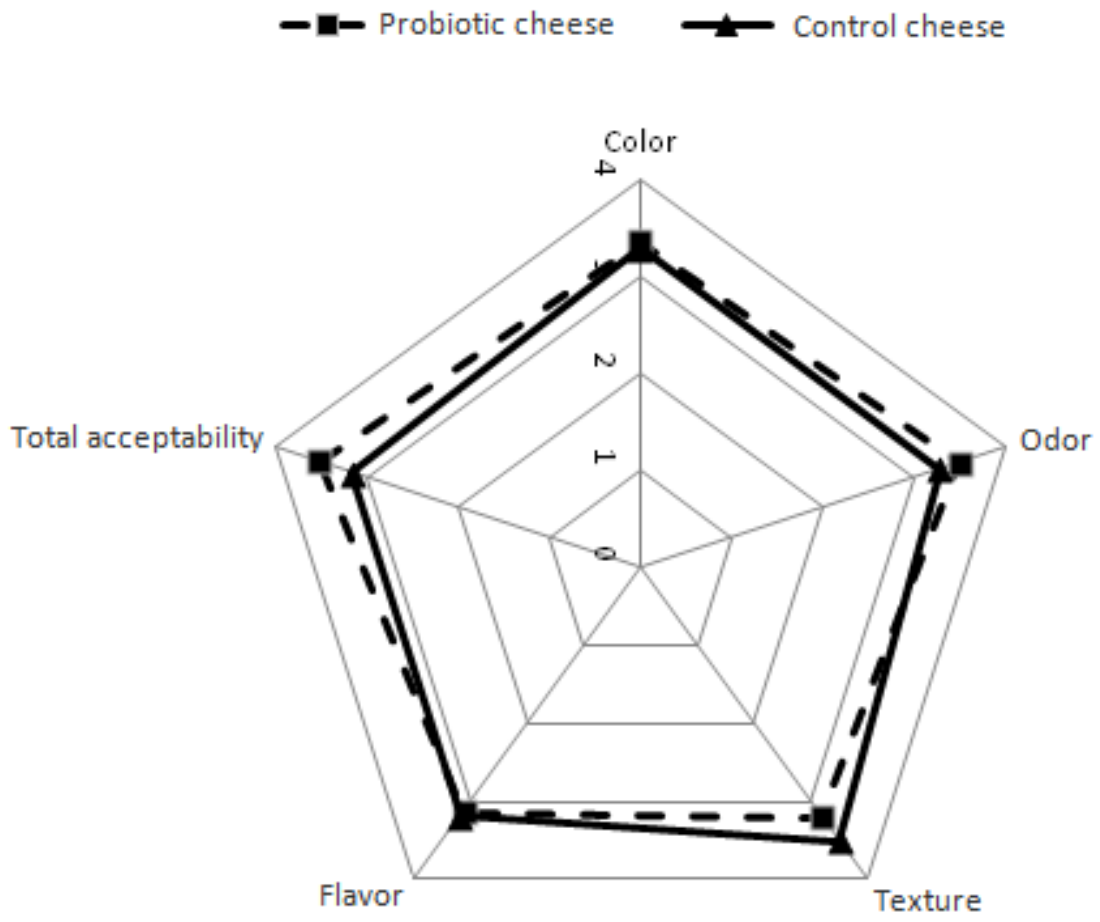

Figure 2. Sensory evaluation.

\section{DISCUSSION}

The symbiote added significantly impact not in the chemical composition of the cheeses. Similar results were obtained by Kasimoglu et al. (2004), who found that the addition of probiotic bacteria in cheese did not influence the final composition of the probiotic food. When Araujo et al. (2009) developed a symbiotic type cottage cheese using Lactobacillus delbrueky UFV $\mathrm{H} 2 \mathrm{~b} 2 \mathrm{O}$ as probiotic microorganisms and inulin as prebiotic agent, they found that the use of these agents do not alter the physicochemical characteristics of processed cheese. In other studies on probiotic cheeses, Ong et al. (2007) found differences in some of the parameters of the overall composition between control and probiotic cheeses. These variations were attributed to the difficulty of controlling the composition of cheeses made at laboratory scale because they worked with batches of 10 to $25 \mathrm{~L}$. It has also been observed that variations in the fat content may modify proteolysis and syneresis reactions of the cheeses (Fenelon et al., 2000; Michaelidou et al., 2003). The difference between the initial and final composition of the different cheeses was due to moisture loss by dehydration resulting to the syneresis that ocurred during the storage of cheeses in refrigeration at $4^{\circ} \mathrm{C}$.

The $\mathrm{pH}$ of the medium is a critical factor that affects the survival of the probiotic microorganism, because the microorganisms' sensitivity to acid is a phenomenon which varies between species and even between strains within a species. Michaelidou et al. (2003) mention that the yeast $S$. boulardii is relatively more resistant to acid compared with Lactobacillus and other bifidobacteria. Boylston et al. (2004) mention that the higher $\mathrm{pH}$ values that present the cheeses compared with those of the fermented milks, which is 3.7 to 4.3 units, turned to the 
cheeses in a less aggressive and more stable food for the survival of microorganisms and of course for the elaboration of probiotics foods. Ong et al. (2007) found that the addition of probiotic bacteria in a food is reflected in a decrease in $\mathrm{pH}$ of the functional food obtained, due to the acidifying capacity of the microorganism.

From a microbiological view point, the symbiotic cheese obtained is harmless because the quantification of the main pathogens tested were below the maximum permissible limits marking the NOM. The food safety must to be guaranteed in each link of the food chain from farm to table, especially with those foods considered as high risk foods such as milk and dairy products, and to ensure their safety, it is necessary to implement good hygiene practices, good manufacturing practices and the implementation of systems of quality assurance as the Hazard Analysis and Critical Control Points at each stage of the symbiotic cheese manufacturing process (Vilar et al., 2011).

Several authors (Stanton et al., 2001; Kailasapathy, 2006; Masuda et al., 2005) has shown the importance of achieving a high probiotic microorganism count at the beginning of the shelf life of the functional food and to maintain these counts to levels of $10^{7} \mathrm{CFU} / \mathrm{g}$ throughout all shelf life of the food in order of the food to exercise the expected probiotic effect, once this has been ingested within its shelf life period. Masuda et al. (2005) developed a probiotic cheese by incorporation of $L$. acidophilus La- 5 and the viability of the microorganism remained above $10^{7} \mathrm{CFU} / \mathrm{g}$ after three weeks of refrigeration storage at $4^{\circ} \mathrm{C}$. Apparently this organism was well adapted to specific environmental conditions; results similar to those were obtained in this study. Gardiner et al. (1998) state that the closed matrix of the cheese and its relatively high fat content, constitute a protective environment to the viability of probiotic microorganisms.

Beyond the advantages that dairy products present like vehicles of probiotics, usually their survival in this type of food has been shown to be highly variable. Indeed, despite numerous favorable results, it has been observed that some limitations in the preservation of the viability of probiotic bacteria due to the microenvironmental conditions of the foods, generally are not the ideal conditions for growth and microbial activity, and by that, the degree of survival of the microorganisms is mainly due to its sensitivity to stress caused by the charac-teristics of the food, and environmental conditions of storage and preservation (Boylston et al., 2004). It has used the microencapsulation of the probiotic microor-ganism in addition with the prebiotic to increase the probiotics survival in the developed symbiotic food (Aqilah, 2010).

The addition of the symbiont $S$. boulardii inulin in the cheeses, impact positively the quality sensory attributes evaluated. Similar results were obtained by Kailasapathy (2006), who found that the addition of probiotic cultures either in the free or encapsulated states did not significantly affect appearance and color, acidity and flavor, except in the texture of the yogurts over its storage period. Meanwhile, Araujo et al. (2009) did not observe statistically significant differences ( $p>0.05$ ) in taste, texture and total acceptability between the symbiont type cottage cheese made with $L$. delbrueki and inulin, and the control cheese, both stored during three and 15 days at $4^{\circ} \mathrm{C}$.

\section{Conclusions}

It was possible to obtain a symbiotic cheese with the recommended concentration of probiotic microorganisms for that cheese can exert the beneficial effects on host health. The symbiotic cheese formulated with the $S$. boulardii yeast e inulin had greater acceptance by the consumers, because of its best organoleptic characteristics than the control cheese. Throughout the shelf life period, the cheese stored at $4^{\circ} \mathrm{C}$, maintained a microorganism count above the level recommended $\left(10^{7}-\mathrm{CUF} / \mathrm{g}\right)$ for that food to be considered as probiotic. The fresh cheese is a good vehicle for the symbiont, because the added probiotic microorganisms maintained adequate viability throughout the shelf life of food.

\section{ACKNOWLEDGEMENTS}

The authors thank the COFAA and the SIP of the National Polytechnic Institute for the financial support granted for the completion of this work.

\section{REFERENCES}

Abosereh NA (2007). Genetic Construction of Potentially Probiotic Saccharomyces boulardii Yeast Strains Using Intraspecific Protoplast Fusion, Microbial Genetics Dept, National Research Centre, Cairo, Egypt 3(3):209-210.

Andrade AE, Fernández CA, Eliana SL, Furtado MM, Alencar MC (2012). Development of a symbiotic cottage cheese added with Lactobacillus delbrueckii UFV $\mathrm{H} 2 \mathrm{~b} 20$ and inulin. J. Funct. Foods 2:85-89.

AOAC (2004). Official Methods of Analysis. Fourteenth edition. Association of Official Analytical Chemists. Washington, U. S. A.

Aqilah MA (2010). Enhancement of probiotics survival by microencapsulation with alginate and prebiotics. MMG 445. Basic Biotechnol. 6: 13-18.

Araujo E A, Carvalho AF, Eleana SL, Furtado MM, Moraes CA (2009). Production of cottage-like symbiotic cheese and study of probiotic cells survival when exposed to different stress levels. Pesqui. Agropecu. Tropical 39(2): 111-118.

Boylston T, Vinderola DC, Ghoddusi GH, Reinheimer BJA (2004). Incorporation of bifidobacteria into cheeses: challenges and rewards. Int. Dairy J. 14: 375-387.

Buts J, Dekeyser PN, Stilmant C, Delem E, Smets F, Sokal E (2006). Saccharomyces boulardii produces in rat small intestine a novel protein phosphatase that inhibits Escherichia coli endotoxin by dephosphorylation. Pediatr. Res. 60(1): 24-9.

Eliana SL, Andrade AE, López CL, Alencar MC, Fernández CA (2013). Survival of Lactobacillus delbrueckii UFV $\mathrm{H} 2 \mathrm{~b} 20$ in ice cream produced with different fat levels and after submission to stress acid and bile salts. J. Funct. Foods 5: 503-507.

FAOMHO (2002). (Food and Agriculture Organization of the United Nations/World Health Organization). Guidelines for the Evaluation of 
Probiotics in Food (London, England, Ontario, Canada. 30 April-1 May).

Fenelon M, O'Connor A, Guinee TP (2000). The effect of fat content on the microbiology and proteolysis in cheddar cheese during ripening. J. Dairy Sci. 83:2173-2183.

Gardiner GE, Ross RP, Collins JK, Fitzgerald G, Stanton C (1998). Development of a probiotic cheddar cheese containing humanderived Lactobacillus paracasei strains. App. Environ. Microb. 64(6):2192-2199.

Granato D, Branco GF, Nazzaro F, Cruz AG, Faria JAF (2010). Functional foods and nondairy probiotic fooddevelopment: trends, concepts and products. Compr. Rev. Food Sci. Food Safety 9: 292302.

Kailasapathy K (2006). Survival of free and encapsulated probiotic bacteria and their effect on the sensory properties of yoghurt. LwtFood Sci. Technol. 39:1221-1227.

Kasimoğlu A, Göncüoğlu M, Akgün S (2004). Probiotic white cheese with Lactobacillus acidophilus. Int. Dairy J. 14(12): 1067-1073.

Masuda T, Yamanari R, Itoh T (2005). The trial for the production of fresh cheese incorporated probiotic Lactobacillus acidophilus group lactic acid bacteria. Milchwissenschaft 60(2):167-171.

Mcfarland L, Bernasconi PV (1996). Saccharomyces boulardii: a review of an innovative biotherapeutic agent. Microb. Ecol. Health Dis. 6: 57171.

Michaelidou A, Katsiari M, Voutsinas L, Kondyli E, Alichanidis E (2003). Effect of commercial adjunct cultures on proteolysis in low-fat Kefalograviera-type cheese. Int. Dairy J. 13: 743-753.

MON (Mexican Official Norms) (1970). All of them available on the following website http://www.facmed.unam.mx/sss/nom/normas\%20oficiales.htm

Ong L, Henriksson A, Shah NP (2007). Proteolytic pattern and organic acid profiles of probiotic Cheddar cheese as influenced by probiotic strains of Lactobacillus acidophilus, L. paracasei, L. casei or Bifidobacterium sp. Int. Dairy J. 17(1): 67-78.

Ramirez CNL (2009). Identification of thermotolerant lactic bacterias isolated from cooked meat products to be used as probiotics. Rev. Iber. Tec. Dairy Foods. 9(1): 81-88.

Sanders ME (2008). Use of probiotics and yogurts in maintenance of health. J. Clin. Gastroenterol. 42: 71-74.

Sangronis E, García J (2007). Effect of the nisin addition in the physical, chemical and sensory properties of "telita" cheese. An. Venez. Nutr. 20(1):12-16

Stanton C, Gardiner G, Meehan H, Collins K, Fitzgerald G, Lynch PB, Ross RP (2001). Market potential for probiotics. Am. J. Clin. Nutr. 73: 476-483.
Vilar M, Rodríguez OJ, Sanjuan M, Diéguez F, Varela M, Yus M (2011). Implementation of HACCP to control the influence of milking equipment and cooling tank on the milk quality. Trends J. Food Sci. 20:1-9.

Yadav V, Sharma L, Binny T, Moza AH (2012). An overview on nutraceuticals as pharmacological agents. Adv. Biores. 3(3): 113128.

Yañez J, Salazar J, Chaires L, Jiménez J, Márquez M, Ramos E (2002). Biotechnological applications of microencapsulation. Adv. Perspective. 21: 313-318.

Zamora VR, Montañez SJL, Martínez FHE, Flores MR, Muñóz RCV, Venegas GJ, Ariza OTJ (2012). Effect of incorporating prebiotics in coating materials for the microencapsulation of Sacharomyces boulardii. Int. j. Food Sci. Nutr. 63(8):930-935.

Ziemer CJ, Gibson GR (1998). An Overview of Probiotics, Prebiotics and Synbiotics in the Functional Food Concept: Perspectives and Future Strategies. Int. Dairy J. 8(5): 473-479. 